\title{
Artes de curar no Brasil holandês: a construção do conhecimento médico e dietético na relação entre Velho e Novo Mundo
}

\author{
Healing arts in dutch Brazil: the construction of medical and dietetical knowledge on \\ the relationship between Old and New World
}

Elisielly Falasqui da Silva Mestranda em História pela Universidade Estadual de Campinas elisfalasqui@gmail.com

\begin{abstract}
Resumo: Buscaremos investigar como se configurou a construção do conhecimento médico e dietético no contexto da ocupação holandesa de Pernambuco (1630-1654), considerando, por um lado, as diversas mudanças no ambiente intelectual europeu, e, por outro, a conjuntura política de consolidação da República dos Países Baixos e de um breve período de expansão ultramarina, que colocou os holandeses em contato direto com o Novo Mundo. Para tal, analisaremos os estudos realizados por Guilherme Piso (1611-1678) e Jorge Marcgrave (1610-1644), quando de sua estadia no Brasil com a comitiva de Maurício de Nassau, entre os anos 1637 e 1644. Abordando especificamente os textos do médico Guilherme Piso, pretendemos observar a constituição de novos saberes, a partir da articulação entre as mudanças no paradigma médico, a alteridade e o projeto de colonização holandês.
\end{abstract}

Palavras-chave: Brasil holandês; Medicina; Dietética.

\begin{abstract}
This article seeks to investigate how the construction of medical and dietetical knowledge was set in the context of the dutch occupation of Pernambuco (1630-1654), considering on the one hand, the several changes in European intellectual environment, and on the other hand, the conjuncture of political consolidation of the Republic of the Netherlands and a brief period of overseas expansion, which put the dutchs in direct contact with the New World. To this end, we will analyze the studies by Willem Piso (1611-1678) and George Marcgrave (16101644), developed in Brazil with the Maurice of Nassau's retinue (1637-1644). Addressing specifically the texts of physician Willem Piso, we intend to observe the creation of new knowledge given by the relationship between the changes in the medical paradigm, otherness and the dutch colonization project.
Keywords:
Dutch
Brazil; Medicine; 
Entre os séculos XVI e XVII, diversos médicos e filósofos naturais fomentaram, nas universidades e academias da Europa, um extenso e polêmico debate sobre o conhecimento do mundo natural e a medicina. Algumas vezes buscando afirmar a filosofia natural e as teorias médicas clássicas em sua atualidade, outras vezes perscrutando as novidades a fim de construir um novo conhecimento e, até mesmo, romper com o antigo, esses médicos e naturalistas forjaram um contexto intelectual que posteriormente viria a ser chamado de revolução científica. ${ }^{1}$

No contexto político, deflagraram-se também diversas disputas, que por sua vez forjariam mudanças sensíveis na configuração política do mundo moderno. Em uma escala específica, nos interessa nesse texto o processo de formação e independência da República das Províncias Unidas dos Países Baixos². Segundo Evaldo Cabral de Mello, a expansão marítima holandesa e sua independência nacional "marcharam de mãos dadas no decurso dos oitenta anos de guerra contra a Espanha (1568-1648)." (MELLO, 2010: 11-12) Dessa forma, um dos campos de ofensiva holandesa foram os domínios coloniais espanhóis e portugueses. ${ }^{3}$ Visando esses objetivos, em 1602, foi criada a Companhia das Índias Orientais ${ }^{4}$, que pretendia quebrar o monopólio ibérico na Ásia, promovendo o comércio e o domínio neerlandês.

Em 1621, o projeto da Companhia das Índias Ocidentais ${ }^{5}$, engavetado durante o período de trégua hispano-neerlandesa (1609-1621), foi finalmente posto em prática. Tratava-se, basicamente da aplicação do modelo da VOC nas Américas e na África

\footnotetext{
${ }^{1}$ A expressão Revolução Científica refere-se às mudanças nas categorias de pensamento ocorridas na Europa entre os séculos XVI e XVIII. O termo popularizou-se após Alexandre Koyré utilizá-lo pela primeira vez, em 1939. Atualmente, essa noção é usada com mais cautela entre os historiadores, que questionam tanto a noção de "revolução", que até o século XVIII "evocava a ideia de um ciclo periodicamente recorrente", quanto de "ciência". Para Steven Shapin, a revolução científica nunca existiu da forma como foi contada, ou seja, como uma ruptura brusca com o paradigma anterior. O autor também não identifica uma "essência" da revolução científica e afirma que as mudanças se deram em diversos sentidos (mecanicismo e teologia natural, por exemplo) e de diferentes formas em toda a Europa. (Cf. SHAPIN, 2000).

2 A República das Províncias Unidas surgiu quando da assinatura da União de Utrecht, em 1579, pelas províncias do norte dos Países Baixos, como reação ao avanço da Coroa espanhola, sobretudo nas províncias do sul. A República só foi reconhecida oficialmente com a assinatura da Paz de Vestifália, em 1648. Heloisa Meireles Gesteira, em História natural do colonialismo holandês, aponta que "é comum fazer referência à República pela sua parte mais próspera, a Província da Holanda, onde se localiza a cidade de Amsterdã." (GESTEIRA, 2006: 105). E, segundo Evaldo Cabral de Mello, em Brasil holandês, a prática de designar por Holanda toda a confederação remonta do século XVII. Também aqui adotaremos a designação de Holanda para toda a República. Utilizaremos tanto o termo "holandês" quanto "neerlandês" para designar aquilo que é referente à Holanda.

${ }^{3}$ Portugal e suas colônias ficaram sob o domínio dos Habsburgos entre os 1580 e 1640.

${ }^{4}$ Referida a partir de agora pela sigla VOC (Vereenigde Oost-Indische Compagnie).

${ }^{5}$ Referida doravante pelas iniciais holandesas WIC (West Indische Compagnie).
} 
ocidental. Com a retomada dos planos de atacar os domínios coloniais ibéricos, Pernambuco foi invadido pelos holandeses em 1630, permanecendo ocupado até 1654. O período que nos interessa, mais especificamente, é o chamado período Nassoviano (1637-1644), quando o conde João Maurício de Nassau-Siegen assumiu o governo do Brasil holandês. Em sua vinda, Nassau trouxe mais de 46 "cientistas, artistas e artífices (...) dos Países Baixos” (BOXER, 1961: 158), entre eles o médico Guilherme Piso (1611-1678) e o botânico Jorge Marcgrave (1610-1644), aos quais coube a missão de observar sistematicamente a natureza e os habitantes do Brasil holandês.

Guilherme Piso nasceu em Leiden, concluiu seus estudos em Medicina na Universidade de Caen, França, em 1634, e chegou ao Brasil em 1638, para substituir o Dr. Guilherme Milaenen, primeiro médico trazido por Nassau para atendê-lo e que faleceu antes mesmo de desembarcar. (Cf. RODRIGUES, 1957: X) Jorge Marcgrave era natural de Liebstad, e tinha formação diversificada, em botânica, matemática e astronomia. Marcgrave foi enviado ao Brasil como ajudante de Guilherme Piso. A partir de seus estudos sobre as plantas, os animais, os habitantes nativos, os astros, as doenças, o clima e outras especificidades da natureza do Novo Mundo, foram publicadas as obras História Natural do Brasil (1648) e História Natural e Médica da Índia Ocidental (1658), das quais falaremos mais a frente.

Pretendemos analisar os estudos de Piso e Marcgrave em sua relação com os seguintes aspectos: primeiramente, a ocupação de Pernambuco, que colocou os holandeses em contato direto com o Novo Mundo, expondo-os não apenas a novidades de maravilhas, mas também a novidades de perigos. Em segundo lugar, a presença de um médico na comitiva, imbuído não apenas de cuidar dos doentes, mas de reunir informações sobre a natureza e as doenças do Novo Mundo e, em certa medida, construir um conhecimento sobre esses temas, deveras útil para um projeto colonizador, posto que versaria sobre a necessidade mais elementar dos colonizadores: a sobrevivência. Nesse sentido, consideramos os escritos sobre medicina, alimentação e dietética um campo promissor para investigarmos a constituição de novos saberes, a partir da articulação entre as mudanças no paradigma médico, a alteridade e o projeto de colonização holandês.

Apesar de autores clássicos nos estudos sobre Brasil Holandês, como Evaldo Cabral de Mello e Charles Boxer, atribuírem a Nassau a idealização do projeto artístico e científico desenvolvido pelos holandeses, Heloisa Gesteira aponta para o desenvolvimento científico-cultural da Holanda no século XVII, considerado sua 
"época de ouro", e interpreta a produção de conhecimento sobre o Novo Mundo como um fator colonizador, ou seja, de conquista desse Novo Mundo. Para ela, a guerra tem desdobramentos políticos, econômicos, sociais e culturais. E o empreendimento científico seria um dos desdobramentos culturais da guerra contra a Coroa espanhola. Dessa forma, o mecenato de Nassau não é suficiente para explicar as atividades desenvolvidas pelos holandeses no Brasil, já que ele próprio também era reflexo da "forma pela qual a cultura científica vinha se impondo na Europa desde o Renascimento". (GESTEIRA, 2004: 15)

Muitos autores apresentam o renascimento do interesse pelos textos clássicos quase como coincidindo com os descobrimentos, e que acabaria, de certa forma, sendo superado por eles, pois a descoberta do Novo Mundo e a necessidade de adicioná-lo ao repertório europeu constituiu um grande desafio à História Natural renascentista, que acabava de se estabelecer como disciplina. Heloisa Gesteira aponta que "os registros produzidos pelos homens que entraram em contato com o Novo Mundo - direta ou indiretamente - contribuíram para fortalecer o movimento renascentista de crítica ao saber herdado da antiguidade, mesmo que este ainda fosse um referencial importante e exemplar.” (GESTEIRA, 2004: 73) Era preciso, então, que os naturalistas superassem o saber clássico europeu que se baseava em autores como Dioscórides e Plínio.

Henrique Carneiro apresenta três momentos de ruptura na história das ciências naturais, antes mesmo da biologia moderna, de Lineu e de Darwin. A primeira ruptura teria se dado no final do século XV, através da difusão de livros clássicos; a segunda, na primeira metade do século XVI, através da busca de maior precisão nas descrições da natureza, a fim de compor as compilações do saber; a terceira ruptura se deu no final do século XVI, quando Garcia da Orta, Nicolas Monardes, Francisco Hernandez, Cristovão Acosta, entre outros, aumentaram o repertório europeu, ao descrever plantas orientais e americanas e ao tentar desenvolver os primeiros métodos de classificação. Keith Thomas destaca o esforço dos naturalistas modernos (a partir do século XVI) em estabelecer um novo sistema de classificação da natureza, menos antropocêntrico. Segundo ele, no século XVII houve uma "revolução das percepções" quanto ao estudo do mundo natural. (CARNEIRO, 2011: 14; THOMAS, 2010: 72) 
De fato, a ciência ${ }^{6}$ ao longo do século XVII passou por grandes mudanças: desenvolvimento da experimentação e do método quantitativo (maior influência da matemática); percepção, por parte de alguns cientistas, de que deveriam aprender com os "leigos"; e, por fim, a aceitação da ciência mecanicista de Descartes (1596-1650), Galileu (1564-1642), Newton (1642-1727), entre outros. (Cf. DEBUS, 1996: 29-33) Não se deve, entretanto, considerar que essas mudanças foram bruscas e radicais, significando uma ruptura total com o paradigma anterior. Segundo Steven Shapin, o que se convencionou chamar de a revolução científica do século XVII, na verdade, "era uma diversidade de práticas culturais que se propunham compreender, explicar e controlar o mundo natural”. (SHAPIN, 2000: 20)

No campo da medicina, desde a Antiguidade, a teoria mais aceita era a humoral. Ela teria nascido com os gregos, entre os séculos VI a V a.C. (Hipócrates), sido modificada para os romanos (Galeno; 130-201 d.C.) e para os árabes (Avicena; 9801037). Basicamente, a teoria humoral "ensinava que a saúde era produto do equilíbrio entre os quatro humores ou fluidos do corpo: sangue, catarro, bílis amarela e negra", sendo cada um equivalente a um dos quatro elementos, que, para os gregos, formavam o mundo: ar, água, fogo e terra, e possuindo qualidades (quente/fria e seca/úmida) combinadas duas a duas e cujo desequilíbrio (aumento ou diminuição dessa qualidade) gerava a doença. Assim, a doença era considerada um desequilíbrio interno e que o próprio organismo do doente combateria, por exemplo, através de “uma rápida febre ou evacuação que queimasse os excessos de um humor, ou líquidos e alimentos que repusessem as faltas." Os médicos deveriam interferir somente em último caso, forçando a eliminação dos excessos através dos purgantes, da sangria e de remédios e alimentos de natureza contrária à da manifestação da doença. (ALFONSOGOLDFARB, 1994: 21-23)

No século XVI, acompanhando as iniciais mudanças nas ciências, essa teoria começou a ser rejeitada, e a principal figura nesse processo foi a de Theophrastus Bombastus Von Hohenheim (1490-1541), ou Paracelso. Sua rejeição à medicina

\footnotetext{
${ }^{6}$ Adotamos algumas vezes o termo "ciência" neste texto, considerando a designação que recebia no século XVII: a de qualquer "corpo de conhecimento propriamente constituído". Com relação a esse tema, nos baseamos no livro A Revolução Científica, de Steven Shapin, cuja principal contribuição é pensar a ciência como "uma atividade social historicamente situada". Em seu livro, Shapin opta por usar os termos "história natural" e "filosofia natural" como alternativa à "ciência", bem como a designação de "filósofos naturais, naturalistas, matemáticos, astrônomos, químicos" como alternativa à "cientista" e "científico", termo que "não se inventou até o século XIX, e não se empregou habitualmente até começos do século XX." (SHAPIN, 2000: 19;26;22)
} 
clássica chegou ao ponto de ele queimar publicamente livros de Galeno e Avicena. "Para ele, a sabedoria seria encontrada apenas no livro sagrado (a Bíblia) e no livro da natureza (com a observação direta e atenta desta)." (ALFONSO-GOLDFARB, 1994:

24) Ele defendia também que os curandeiros populares sabiam mais do que os mestres do passado, pois havia, então, doenças desconhecidas dos antigos, como a sífilis e os ferimentos causados pela pólvora, que só passou a ser usada largamente pelos europeus no século XV.

Mas a questão, para Paracelso, não era apenas a desatualização dos textos antigos perante as novas doenças. Para ele, a própria interpretação dos antigos sobre o que é a doença estava errada. Paracelso não a interpretava como um desequilíbrio no organismo, mas como uma agressão externa, que o corpo, sozinho, não conseguia combater. O papel do médico, nesse caso, seria o de fornecer "ao corpo as mesmas armas do mal que lhe atacava, para que ele tivesse condição de vencer o combate”. Essa ideia se baseava na medicina germânica popular, que considerava que "iguais curam iguais”. (ALFONSO-GOLDFARB, 1994: 24-26) Ao contrário dos remédios usados na medicina clássica, todos mais fracos e feitos à base de ervas, os remédios indicados por Paracelso e os paracelsistas eram fortes e tinham base em minerais, que à época eram considerados por muitos médicos como um veneno a ser evitado.

O embate polêmico entre essas ideias, durante os séculos XVI e XVII, envolveu muitos médicos e naturalistas. Basicamente, a disputa se configurava entre "antigos" (aqueles que valorizavam os estudos dos clássicos como a maior autoridade) e "modernos" (aqueles que queriam uma ciência inteiramente nova). A realidade, entretanto, era mais complexa, e havia muitos "antigos-modernos" e "modernosantigos". ${ }^{7}$ Andrea Vesalius, por exemplo, baseou seus estudos sobre a anatomia humana na dissecação de cadáveres, porém afirmava que seu objetivo era tão somente aprimorar os estudos do mestre Galeno; Georgius Agricola, para escrever o seu De re Metallica, buscou o conhecimento prático dos mineiros, mas sempre dialogando, de alguma maneira, com os clássicos. A lista de exemplos é bastante extensa. Aqueles, porém, que insistiram na tentativa de romper total e imediatamente com a "Antiguidade", foram perseguidos não só no meio intelectual, mas também religioso, a ponto de o "anti-

\footnotetext{
7 Thomas Kuhn, um nome de destaque nos estudos sobre as revoluções científicas, defende que a substituição de um paradigma por outro não ocorre de forma brusca, como uma ruptura total; pelo contrário, parte do paradigma anterior continua residindo no paradigma subsequente. (KUHN, 2009)
} 
galenismo" tornar-se uma acusação investigada pelo Santo Ofício. Quanto a isso, Eugenio Garin observa:

(...) como esquecer que Telésio e Patrizi figuraram no Índex, que Pierre Ramus foi assassinado em Paris na noite de S. Bartolomeu, que Bruno e Vanini foram queimados, e Campanella foi condenado à prisão perpétua, para não falar da condenação de Copérnico e de Galileu, deixando de parte Cartésio, que por medo nunca publicou "O mundo"? (GARIN, 1991: 143)

No que diz respeito aos viajantes, o caso que mais nos chama atenção é certamente o de Garcia da Orta (1501-1568), que escreveu em Colóquio dos simples e drogas e coisas medicinais da India: "Se eu estivesse em Espanha, não me atreveria a falar contra Galeno e os gregos", dando a entender que, uma vez estando em um Novo Mundo (Goa), a autoridade dos antigos não devia prevalecer. Garcia da Orta teve seu livro colocado no Índex e, alguns anos após sua morte, seu corpo foi exumado e queimado pela Inquisição. (RODRIGUES e FIOLHAIS, 2013: 448)

De uma forma ou de outra, esses pensadores contestaram a autoridade institucional das universidades, dos grandes clássicos e da Igreja. Eles:

(...) queriam conhecer, mas agindo; (...) estavam prontos para tudo, mesmo para procurar os segredos da "magia" natural para dominar o mundo, mas empenhados em libertar a "ciência" da "magia". Viviam já num outro mundo, não conciliável com o velho: um mundo sem fronteiras, onde se moviam infindáveis outros sistemas, onde a Terra girava em volta do Sol, onde o homem procurava uma medida de certeza não só cavando dentro de si como Montaigne, mas esforçando-se (ainda como Montaigne) por conhecer melhor os habitantes de terras desde sempre desconhecidas, difíceis de inserir nos quadros teológicos tradicionais. (GARIN, 1991: 143)

Nesse contexto, de embates políticos, disputas territoriais e econômicas, divergências religiosas, florescimento e mudanças culturais, a comitiva de "artistas e sábios" trazida por Nassau realizou a "primeira missão propriamente científica ao Novo Mundo". (GESTEIRA, 2006: 107)

Heloisa Gesteira, em Teatro das coisas naturais, defende que o empreendimento científico realizado pelos holandeses no Brasil foi previamente planejado. Assim, a 
comitiva de Nassau já tinha uma missão antes mesmo de chegar ao Brasil. A seleção de Guilherme Piso e Jorge Marcgrave para a comitiva teria sido articulada pelos diretores da WIC e por amigos influentes que ambos tinham, sendo o principal deles Johannes de Laet, que era um importante elo entre a Companhia das Índias Ocidentais, a Universidade de Leiden e a empresa tipográfica Elsevier.

Para realizar suas observações, Piso e Marcgrave realizaram expedições pelo nordeste brasileiro e também contavam com um lugar privilegiado para estudos: um jardim botânico construído no Palácio de Friburgo, na Ilha de Antônio Vaz, que reunia diversas espécies animais e vegetais do mundo conhecido e recém-conhecido. Além disso, Guilherme Piso, para escrever seus tratados de medicina, demonstrou ter observado com frequência as práticas de cura indígena e realizado experimentações com elas, assim como também dissecações em cadáveres e vivissecções em animais do Jardim do Conde. ${ }^{8}$

O resultado desses estudos foi um levantamento de 415 plantas, 367 animais e 22 doenças, mais de 400 ilustrações da fauna e da flora, uma relação das virtudes médicas de 114 plantas, e diversas observações sobre os costumes e a terapêutica indígena. Quanto às contribuições científicas, acredita-se que Piso foi o primeiro a estabelecer que o veneno das cobras é proveniente de seus dentes e não do corpo todo, como pensavam os europeus até então, e Marcgrave é considerado um dos pais da ictiologia, mérito alcançado pelo minucioso estudo sobre peixes que ele realizou no Brasil - das 367 espécies de animais que ele descreveu, 103 são de peixes. (Cf. CARNEIRO, 2011: 19-20)

Após voltar a Europa, em 1645, Nassau entregou os estudos de Guilherme Piso e Jorge Marcgrave a Johannes de Laet, que foi o responsável pela edição e publicação, em 1648, de Historia Naturalis Brasiliae. Nela, reuniram-se quatro livros de Piso (Medicina Brasiliensis) e oito livros de Marcgrave (Historiae Rerum Naturalium Brasilium), os quais tiveram que ser decodificados e organizados pelo próprio Laet, uma vez que Marcgrave havia falecido, em 1644, em Angola. É importante ressaltar a participação de Laet nesse empreendimento, uma vez que ele pode indicar a relação entre os interesses expansionistas da WIC e os empreendimentos científico-culturais da Universidade de Leiden, fundada em 1575 como "uma escola de preparação dos funcionários da burocracia do novo Estado independente, dos regentes, da nobreza e

\footnotetext{
8 Para mais informações sobre o jardim, conferir o artigo "João Maurício e suas plantas", de Maria Angélica da Silva. (TOSTES e ali, 2005: 197-224)
} 
também dos predicantes para a igreja reformada." (GESTEIRA, 2006: 107-108) Leiden se tornou um local de afirmação intelectual protestante e referência para universidades na Europa. ${ }^{9}$ Piso e Marcgrave mantiveram contato com acadêmicos de Leiden em todo o período que estiveram no Brasil, e a ideia de usar o conhecimento como estratégia de dominação e vitória sobre a Coroa espanhola estava presente no pensamento de muitos intelectuais holandeses, incluindo Johannes de Laet.

Em 1658, Piso publicou De Indiae Utriusque Re Naturali et Medicae, obra que também apresentava os estudos que ele e Marcgrave realizaram no Brasil, acrescentando estudos referentes a Java, realizados por Jacob Bontius. Porém a nova edição apresentava modificações e apropriações por parte de Piso dos textos de Marcgrave, o que rendeu àquele acusações de plágio. Na composição do livro, temendo que essa acusação fosse feita, Piso refere-se muitas vezes a Marcgrave como seu assistente, e afirma que deste recebeu, por empréstimo, "algumas gravuras e anotações colhidas em nossas viagens." E completa: "pois, quando o serviço público me negava o lazer necessário, pedi-lhe que me ajudasse com seu diligente trabalho.” (PISO, 1957 [1658]: 249)

Heloísa Gesteira aponta para a ideia que se tinha do autor no século XVII e trata a obra como uma produção feita por muitas mãos, e não apenas as de Piso e Marcgrave, o que o seguinte trecho escrito por Piso parece confirmar:

Pouco importa que as nossas descobertas a ele ou a mim fossem atribuídas, ou que viessem à luz com o nome de um ou de outro, desde que estas descobertas dissipassem algumas dúvidas e revelassem erros e fossem úteis aos doentes e médicos, tanto no Novo como no Velho Mundo. (PISO, 1957 [1658]: 249)

Ainda quanto à originalidade das obras, Henrique Carneiro lembra-nos que "os autores originais da maior parte das informações obtidas pelos naturalistas (...) foram as populações indígenas que por aqui viviam antes da chegada dos colonizadores." (CARNEIRO, 2011: 21). De qualquer forma, os livros de Piso e Marcgrave são considerados os primeiros levantamentos médico-botânicos da flora e fauna brasileiras, servindo de referência em História Natural do Brasil até, pelo menos, o século XIX.

\footnotetext{
${ }^{9}$ A Universidade de Leiden foi uma das primeiras a possuir um anfiteatro de anatomia, um observatório astronômico e um jardim botânico.
} 
Optamos, nesse texto, por enfocar a obra de Guilherme Piso, uma vez que ele atentou-se para questões que poderão enriquecer a reflexão, como a aceitação (ou não) da terapêutica indígena, a adaptação dos europeus por meio do reconhecimento de plantas medicinais - e também de perigos - até então desconhecidas, reconhecimento e descrição de doenças comuns no Novo Mundo, indicações dietéticas, etc. Além disso, a escolha de analisar mais detidamente os escritos de Guilherme Piso deve-se a sua condição de médico inserido no contexto já descrito anteriormente e, portanto, confrontado com diversas questões sobre o saber natural e médico, que ele busca, em certa medida, organizar em seus escritos.

Em História Natural e Médica da Índia Ocidental, são cinco os livros de Guilherme Piso: 1) Dos ares, das águas e dos lugares; 2) Da natureza e cura das doenças familiares à Índia Ocidental e sobretudo ao Brasil; 3) Dos animais aquáticos, voláteis e terrestres que se podem comer; 4) Das árvores, frútices e ervas medicinais e alimentícias, que nascem no Brasil e nas regiões vizinhas; 5) Das plantas daninhas, dos animais venenosos e seus antídotos; ao que estão anexadas vivissecções de certos animais, bem como algumas metamorfoses de insetos. Constam ainda, escritas por Piso, dedicatórias, saudações e cartas, às vezes destinadas aos leitores, às vezes a um leitor específico. Entre esses capítulos, optamos por dar maior ênfase ao segundo e ao quarto, que tocam mais diretamente nos temas da medicina e da dietética.

Antes de passarmos aos dois capítulos selecionados, cabem alguns comentários sobre os outros três. Sem intenção de aprofundar, observamos que só os nomes dos capítulos já fornecem algumas informações sobre o pensamento médico e científico de Piso e sua posição perante as transformações que vinham ocorrendo na Europa, bem como a influência do fato de ele estar escrevendo em um Novo Mundo e sobre esse Novo Mundo, utilizando-se dos instrumentos que ele já tinha adquirido em sua formação na Europa, mas também se apropriando de outros, novos, apreendidos com os habitantes desse Novo Mundo.

O primeiro capítulo, Dos ares, das águas e dos lugares, faz clara referência a Hipócrates, não só de forma indireta, imitando sua forma de começar um livro de medicina, mas também ao citá-lo diretamente: "Não se pode inventar mais adequada norma para ordenar ou instituir a Medicina, entre gentes remotas, do que a transmitida por Hipócrates, o melhor autor de tudo que há de bom nesta arte (...)”. Dessa forma, Piso se alinha com os médicos "clássicos", os "antigos" no debate europeu. Ele concorda que antes de se falar sobre as doenças e curas é necessário conhecer "as coisas 
com as quais o homem costuma viver", ou seja, o ambiente em que vive, seus hábitos, sua alimentação, etc., pois tudo isso pode interferir nos "humores". (PISO, 1957 [1658]: 29-30)

Entre os autores antigos, não é apenas Hipócrates que Piso cita. Embora Hipócrates tenha maior destaque, logo seguido de Galeno, também são citados Tácito, Aristóteles, Plínio, Dioscórides, entre outros. Porém muitas vezes Piso os cita para corrigi-los, como no caso seguinte: “Ao contrário do que Aristóteles, Plínio e outros julgaram, não somente este clima é habitável, mas os orvalhos perpétuos e as chuvas e as brisas agradáveis do mar o fazem temperado e fértil por toda parte (...)" (PISO, 1957 [1658]: 33) Por outro lado, ao descrever espécies do Novo Mundo, Piso cita autores contemporâneos a ele: alguns que não tinham estado na América, como Charles L'Ecluse, médico e professor de botânica na Universidade de Leiden, e muitos cronistas espanhóis, como Francisco Ximenes e Nicolas Monardes, o que denota o conhecimento prévio que Piso tinha sobre o Novo Mundo.

Quanto à medicina, Piso frequentemente faz comparações entre os ameríndios e os romanos e gregos. Algumas relações parecem ser um tanto forçadas pelo autor, por exemplo, quando ele descreve uma doença que ele diz ser comum na América, "que ataca os nervos e causa profundo torpor aos membros. Sua natureza ninguém (...) descreveu. Chamam-na os lusitanos Air (...)", porém, em seguida, após discorrer sobre algumas observações que ele teria feito da doença, inclusive através da "dissecção de um etíope", Piso cita Hipócrates e Galeno, tentando encaixar essa doença, que ele próprio confirmou não haver sido descrita anteriormente, na tradição médica clássica. (PISO, 1957 [1658]: 93-94)

O título do terceiro capítulo, Dos animais aquáticos, voláteis e terrestres que se podem comer, denota um pensamento utilitário na descrição e classificação dos animais observados. Uma das principais críticas feitas atualmente aos estudos de Piso e Marcgrave é justamente sua visão utilitarista da natureza, que direcionou seus olhares para animais de alto valor econômico, de grande porte ou considerados pelos europeus como exóticos, além da seleção de animais e plantas que teriam maior "utilidade" quanto à alimentação e à prática da medicina. Caberia questionar, porém, se isso mostra que Piso e Marcgrave estavam alheios à "revolução das percepções" referida por Keith Thomas, na qual a classificação utilitária da natureza perdia espaço, ou se essa classificação foi adotada apenas por melhor atender seus objetivos - lembrando que 
esse conhecimento foi produzido de forma direcionada a corresponder os interesses da WIC, de Nassau, da Universidade de Leiden, etc.

Essas questões demonstram a complexidade do contexto intelectual do século XVII. Enquanto esses exemplos citados anteriormente vinculam Piso ao grupo dos "antigos" no debate europeu, o quinto capítulo traz alguns aspectos novos: as anotações sobre metamorfoses e as vivissecções realizadas por Piso e Marcgrave indicam que eles se preocuparam em realizar uma observação sistemática do que estavam estudando, ou seja, buscaram um estudo prático, que superasse, de certa forma, a teoria dos autores antigos.

É particularmente interessante a ênfase que Piso dá ao estudo das plantas daninhas, dos animais venenosos e seus antídotos. Como já dissemos, Piso teve um grande destaque no estudo dos venenos. Ao refletir sobre a relação de alteridade perante um mundo novo versus a adaptação a esse mundo, consideramos que, para os viajantes, como Piso, conhecer a natureza, as propriedades das plantas, os perigos dos animais, entre outras coisas, era também - e talvez, sobretudo - uma questão de sobrevivência. E esse aspecto interferia na apreensão que os viajantes faziam do Novo Mundo. É notório, por exemplo, que Piso tenha dividido as espécies entre venenosas e não venenosas e que essa divisão tenha sido dispensada pelo médico Christian Mentzel, que organizou o Teatro das Coisas Naturais do Brasil ${ }^{10}$. Ora, saber se uma espécie era venenosa ou não era mais imprescindível na América, de onde Piso escrevia, posto que ainda se estava conhecendo a natureza, e o contato com uma espécie venenosa tornava-se ainda mais perigoso, do que na Europa, de onde Mentzel escrevia.

É provável que, apesar de considerar ainda a autoridade dos clássicos, Piso estivesse sensível a essas mudanças, pois, no final do primeiro capítulo escreve:

(...) as modernas navegações do Novo Mundo confirmam que, assim como variam os hábitos e gêneros de vida dos povos segundo os diversos climas do mundo, assim também diferem as doenças e os gêneros de morte; e assim como as antigas doenças costumam extinguir-se, do insólito giro e inclinação dos astros, bem como do clima da terra austral, soem gerar-se novas. (PISO, 1957 [1658]: 72)

\footnotetext{
${ }^{10}$ Coleção de figuras que retratam a natureza brasileira, também elaborada pela comitiva de Nassau.
} 
O segundo capítulo, selecionado para uma análise mais detalhada, nos traz justamente exemplos dessa percepção da novidade por parte de Piso. Após fazer uma introdução analisando a medicina nativa e as possibilidades de se aplicar, no Brasil, a medicina europeia, Piso enumera e explica 17 grupos de doenças e suas curas. ${ }^{11}$ Das doenças enumeradas, apenas uma não tinha sido descrita anteriormente e para o tratamento de qualquer uma delas, Piso indica remédios nativos, reproduzindo, inclusive, os nomes indígenas de praticamente todas as plantas nativas citadas.

Já na carta ao leitor, Piso afirma: "[firmado] no testemunho dos sentidos, submeti ao exame e à praxe tudo o que do amplíssimo teatro da Natureza observei ou recebi dos indígenas." $\mathrm{Na}$ introdução do segundo capítulo, ele explica-se: "Embora se encontrem nessa barbárie muitíssimos hábitos grosseiros, corruptos e indignos da arte hipocrática, existem contudo não poucos utilíssimos, que rivalizam com os da antiguidade e podem até impressionar os médicos mais eruditos.” Ainda justificando, ao público europeu, sua consideração pela terapêutica indígena, questiona: se muitos rudimentos da medicina e outras artes foram aprendidos através dos animais, "quem duvidará que, também dos mortais mais distantes da dogmática ciência de curar, não possa derivar até nós grande cópia de salubérrimos e secretos remédios e antídotos e modos de cura desconhecidos dos antigos?" (PISO, 1957 [1658]: 74)

O contato entre europeus e indígenas deu-se pela chave da alteridade. ${ }^{12}$ Nos trechos citados acima podemos identificar visões comuns dos europeus sobre esse outro indígena: é o bárbaro, com costumes grosseiros e indignos; é o selvagem, muito ligado à natureza, é como que uma parte dela, um animal. Piso faz outras detrações aos indígenas: considera-os preguiçosos, indolentes, supersticiosos e muito dados às bebidas e aos prazeres. Porém, quanto às práticas de cura, a maioria delas é considerada por Piso com grande apreço. Não só por Piso, mas por diversos outros viajantes. Sobre isso Sérgio Buarque de Holanda escreve: "Práticas indígenas, que tinham todos os requisitos para alarmar ou escandalizar os europeus encontraram (...) acolhida inesperadamente

\footnotetext{
${ }^{11}$ Catarros; males dos olhos; estupor dos membros; obstruções das vísceras naturais; hidropisia; prolapso da cartilagem mucronada; fluxos do ventre; tenesmo; cólera; disenteria; fluxo hepático do ventre; úlcera e inflamação do ânus; lombrigas; lues índica; feridas e úlceras; furúnculos e impigem.

${ }^{12}$ Segundo François Hartog, a retórica de alteridade é própria das narrativas de viagem, em que "um narrador, pertencente ao grupo $\mathrm{a}$, contará b às pessoas de a: há o mundo em que se conta e o mundo que se conta. (...) Dizer o outro é enunciá-lo como diferente - é enunciar que há dois termos, a e b, e que a não é b (...) Mas a diferença não se torna interessante senão a partir do momento em que a e b entram num mesmo sistema. Não se tinha antes senão uma pura e simples não-coincidência. Daí para a frente, encontramos desvios, portanto uma diferença possível de ser assinalada e significativa entre os dois termos". (HARTOG, 1999: 229)
} 
favorável." (HOLANDA, 1994: 78) Piso conta a experiência que fez com que ele diminuísse seus preconceitos quanto à medicina indígena e passasse a observá-la com maior atenção:

Lembro-me de que os bárbaros nos acampamentos, por meio de gomas frescas, sucos e bálsamos, livraram do ferro e do fogo e restabeleceram com êxito os membros dos soldados feridos por balas de espingardas, que estavam para ser amputados pelos cirurgiões europeus, lusitanos e batavos. Sou igualmente testemunha ocular de que nos hospitais foram por eles curadas, só com o suco de tabaco, as úlceras rebeldes e as gangrenas. Ainda mais: livraram logo da morte, só com a bebida da raiz fresca de Iaborandí, moribundos envenenados pela ingestão de cogumelos venenosos e outros tóxicos, apesar de eu e outros netos de Galeno, tomados de não pequeno pejo, nos termos esforçado em vão depois de repetidas aplicações dos alexifármacos e triagas antidotais. E assim, depois consenti em ser auxiliado por tais colegas bárbaros, não tanto habituados na marcha da saúde dos nossos pelo tato das artérias, quanto em fornecer abundantes conselhos, na sobredita maneira. (PISO, 1957 [1658]: 76)

Essa passagem fornece muitos elementos para a análise que propomos nesse texto. Primeiramente, precisamos dizer que Piso se filia à tradição médica clássica, e reitera sua posição várias vezes na composição de seu texto. Ele faz também muitas críticas aos chamados "modernos", sobretudo em uma carta a um acadêmico de Leiden e amigo seu, D. J. Antonides Van Der Linden. Para Piso, os modernos são aproveitadores, que abandonaram a medicina antiga por "falácias feiticeiras" e para confiar no "espírito leviano da plebe"; eles "procuram fama com a novidade" e lucro com os remédios compostos por eles inventados. Contra esses "falsos caminhos", o médico adverte que todas as descobertas "devem ser exatamente verificadas e diligentemente conferidas com as opiniões dos antigos e mais dignos de fé, sobretudo de Hipócrates, o mais fiel intérprete da Natureza e da Medicina". (PISO, 1957 [1658]: $79 ; 558-559)$.

Dessa forma, Piso passa a ter uma posição parecida com a de Vesalius e Agricola, já citados como "antigos-modernos" ou "modernos-antigos", ou seja, aqueles que não tomaram uma posição radical nem no sentido de aderir às novas teorias, 
desprezando o conhecimento anterior, nem no sentido de abraçar-se perpetuamente aos ensinamentos antigos e desconsiderar qualquer novidade. No caso de um viajante pelo Novo Mundo, como Piso, seria praticamente impossível desconsiderar as novidades. No excerto citado anteriormente, notamos como algo novo e sem correspondência na teoria médica clássica os ferimentos de espingarda e os envenenamentos por plantas nativas da América. O próprio Piso nota que a terapêutica galênica não surtiu o resultado esperado e que o conhecimento europeu não fora suficiente e por isso não se apega apenas às teorias antigas, mas defende que os médicos aprendam "a fruir igualmente do nosso século e da antiguidade, e seguir a via de cura mais isenta de perigos." (PISO, 1957 [1658]: 561). Note-se também que, mais como os modernos do que como os antigos, Piso coloca-se a ouvir leigos, ou seja, pessoas não versadas na arte hipocrática, e, em seu caso, com um agravante: indígenas.

Márcia Moisés Ribeiro, considerando a experiência dos lusitanos, sobretudo no século XVIII, com a descoberta de ouro nas Minas e a necessidade de desbravar o sertão, afirma que para "vencer os obstáculos da natureza" para atingir os objetivos das explorações era necessário adaptar-se e, assim, a "submissão aos conhecimentos indígenas foi extremamente necessária." Ela afirma ainda que "diante da falta de físicos e cirurgiões e do desconhecimento da natureza e das drogas medicinais do Brasil, o colonizador mais assimilou os hábitos da terra do que impôs os seus aos povos conquistados". (RIBEIRO, 1997: 17 e 28). Acreditamos que isso se estenda também aos demais colonizadores ou viajantes que aqui estiveram, como os neerlandeses, e que essa seja a maior peculiaridade de se estudar as práticas de cura e a alimentação: numa relação colonial, muitas vezes esses elementos invertem, ainda que momentaneamente, a figura do dominado e do dominador, por criar uma dependência deste com relação àquele.

Vemos ainda no excerto citado que está posta a questão da alteridade: o outro, indígena, é bárbaro, desconhecedor da "arte hipocrática" e, a princípio, Piso parece expressar um misto de descrédito e surpresa ao ver as curas realizadas por esse outro. Entretanto, após ver que a terapêutica aplicada pelos indígenas era, em muitos casos, mais satisfatória em seus resultados, Piso inclina-se mais à curiosidade médica e à necessidade de adaptar-se à nova realidade, que oferecia novas plantas e também novos perigos e doenças, do que aos preconceitos que ele poderia ter com relação ao outro, e consente, enfim, ser auxiliado por este. Ora, provavelmente ele não estava em posição de negar o auxílio dos indígenas, que, embora já tivessem transmitido uma parte de seus 
conhecimentos da flora aos europeus que chegaram anteriormente a Piso, ainda eram os maiores detentores desse saber: os indígenas, com seus conhecimentos das propriedades medicinais das plantas, não precisavam recorrer aos remédios europeus da botica, entretanto, seja pela falta de medicamentos nas boticas, seja pela má condição ou inacessibilidade destes, os europeus aprenderam a recorrer aos remédios indígenas da floresta. $^{13}$

Também para a dietética, o conhecimento da flora e fauna, proveniente dos indígenas, era fundamental. Antes de prosseguirmos, é necessário lembrar a relação fundamental entre medicina e alimentação no século XVII, representada na importância que os tratados de dietética assumem nesse período. ${ }^{14}$ Piso observou que, "nas Índias", todos os que exercem a arte de curar, "indígenas, estrangeiros, Molatos e Mamolucos de raça mestiça, são muito escrupulosos na prescrição da dieta aos doentes" (PISO, 1957 [1658]: 76) e o próprio Piso, para todas as doenças citadas, faz indicações dietéticas.

Por vezes aparecem restrições alimentares: "a comida seja ótima de nutrimento, porém seca" (PISO, 1957 [1658]: 95); "escolham-se alimentos antes assados que líquidos ou fritos, muitas vezes e aos poucos" (PISO, 1957 [1658]: 107); "quanto à alimentação, convém usar principalmente alimentos frios e fortificantes; evitem-se os excitantes mais do que um cão ou serpente" (PISO, 1957 [1658]: 116). Outras vezes as indicações são de como deve ser o comportamento alimentar do doente ou daquele que queira conservar a saúde: "alimente-se repetidas vezes e aos poucos, por causa da perda das forças, e tome bebidas quentes" (PISO, 1957 [1658]: 93); "se deve observar com rigoroso escrúpulo a prescrição de Celso (...) que diz: 'Se alguém durante o dia encher o estômago, depois da refeição não deve expor-se ao frio nem ao calor, nem entregar-se ao trabalho'." (PISO, 1957 [1658]: 104).

Há também indicações de alimentos com propriedades diuréticas, adstringentes, antidotais, purgativas, entre muitas outras: “a Pacóba e a Banána, semiassadas, sejam

\footnotetext{
${ }^{13}$ Piso faz diversas referências a lições que os europeus já tinham aprendido com os indígenas, e afirma que "na cura dos ferimentos e úlceras muitos lusitanos e brasileiros, pela longa prática se tornaram mais experientes e têm florestas de remédios em qualquer parte, em todo o ano, ao alcance da mão" (p. 122). Quanto aos indígenas, porém, escreve que para curar a gonorreia, por exemplo, "tão salutares remédios (...) encontram os aborígines, que raramente lhes é necessário recorrer aos estrangeiros, à venda nas boticas.” (PISO, 1957 [1658]: 120). Márcia Ribeiro aponta diversos problemas relacionados às boticas: falta de medicamentos; demora para que chegassem da Europa; deterioração por ficarem muito tempo nos navios ou nas prateleiras; falta de fiscalização; etc. (RIBEIRO, 1997: 24)

${ }^{14}$ Sobre essa relação, ver FLANDRIN, Jean-Louis. (1998) Da dietética à gastronomia, ou a libertação da gula. In: FLANDRIN, Jean-Louis; MONTANARI, Massimo. História da Alimentação. 2. ed. São Paulo: Estação Liberdade. pp. $667-698$.
} 
ingeridas frequentemente como alimento medicamentoso" (PISO, 1957 [1658]: 112). Muitas vezes, é difícil separar remédio e alimento, pois grande parte das plantas citadas assumem as duas funções. Mesmo a forma de preparação de alguns remédios se assemelha muito com receitas para preparação de alimentos, o que mostra a ligação entre cozinha e medicina: "os caldos para uso do doente temperem-se com o açafrão indígena Urucú, a pimenta brasileira sativa e silvestre; e, se nada o impedir, com cebolas e alhos" ((PISO, 1957 [1658]: 104). Segundo Bruno Lauriox, "a arte de temperar assemelhava-se à prática farmacêutica" (LAURIOX, 1998: 488). Além disso,

A cocção dos alimentos é considerada um progresso para a saúde. Ela é identificada com a própria descoberta da medicina por um dos textos médicos mais antigos do corpus de Hipócrates, o De antiqua medicina, e essa ideia aparece constantemente nas obras posteriores. Os diferentes modos de cocção tornam-se inclusive meios para modificar as propriedades naturais dos alimentos com a finalidade de trazer benefícios para a saúde. (MAZZINI, 1998: 261)

Essa variedade de plantas medicinais e alimentícias foi o que mais chamou a atenção de Piso. Ele descreve especialmente encantado os resultados obtidos com o tabaco e a ipecacuanha, que ele considerou a "âncora sagrada" e só não a exaltou mais por receio de parecer, aos olhos dos leitores, excessivo. (PISO, 1957 [1658]: 106).

Embora Piso cite e descreva algumas plantas e seus usos nos demais capítulos, é o quarto capítulo que trata especificamente Das árvores, frútices e ervas medicinais $e$ alimentícias. Neste, são descritas quase 200 espécies de plantas, acompanhadas por diversas figuras que, ao que consta, foram desenhadas por Marcgrave. Piso optou por apenas discorrer sobre os vegetais alimentícios e medicamentosos cujas virtudes não tivessem sido "já suficientemente bem expostos por outros" e também os que "são de uso na Medicina, e empregados por outros e por mim com bom êxito para incremento da nossa arte". Tomando como modelo Dioscórides, Piso explica que sua intenção não era de fazer um levantamento e simples exposição das maravilhas da Natureza, mas elencar indicações úteis à medicina. (PISO, 1957 [1658]: 248) ${ }^{15}$

\footnotetext{
${ }^{15}$ Como já falamos sobre as mudanças no estudo botânico europeu e a posição de Piso perante essa mudança, cabe ainda lembrar, para não perdermos de mente que se trata de um contexto intelectual complexo, que na Idade Moderna, como nas outras épocas, "o principal estímulo para os estudos
} 
Piso explica ainda a classificação adotada por ele: “(...) não me adstringi tão escrupulosamente à ordem habitual dos botânicos (...) Mas, dos vegetais mais importantes e usuais, desci aos outros, consoante se ofereciam nos diversos lugares e circunstâncias". (PISO, 1957 [1658]: 249) É interessante notar, porém, que a primeira planta descrita por Piso é a cana de açúcar. A partir do século XV, há um crescimento contínuo da demanda por açúcar, proveniente da América. Alain de Lemps afirma que, enquanto nas colônias espanholas a produção de açúcar, mesmo em grande quantidade, era para consumo local, no Brasil quase todo o açúcar produzido era enviado à Europa: "para Lisboa e sobretudo para Antuérpia, que se tornou, em detrimento de Veneza, o grande centro de refinação e redistribuição do açúcar na Europa do Norte” (LEMPS, 1998: 612-613). Piso escreve que "nenhuma mercadoria desta terra existe que dê mais lucro e ganho aos negociantes" (PISO, 1957 [1658]: 251).

Aqui parece se configurar novamente o uso da ciência como uma arma da expansão holandesa, pois, se para eles conhecer era sinônimo de dominar, o conhecimento da cana de açúcar não poderia ocupar outro lugar senão o de destaque que Piso lhe reservou. ${ }^{16}$ Indicativo de que o estudo do açúcar foi mais valorizado por questões econômicas do que por suas virtudes medicinais é que estas foram abordadas apenas no último parágrafo, de forma breve e apenas repetindo o que já era conhecido “na maior parte, dos europeus (...)" (PISO, 1957 [1658]: 253). Se seu interesse fosse discorrer sobre uma planta já conhecida dos europeus, mas com virtudes medicinais ainda desconhecidas, podemos pensar que seria mais compreensível que ele falasse sobre o cacau, o que, porém não aconteceu: Piso cita a bebida chocolate, mas não faz menção nem à planta do cacau, nem aos seus usos medicinais. $\mathrm{O}$ que chama mais a atenção ainda é que, segundo Leila Mezan Algranti, um dos usos medicinais que os

botânicos era medicinal", tanto que os primeiros botânicos eram médicos e boticários, preocupados com as “ 'virtudes' das plantas. A descoberta do Novo Mundo intensificou a busca das plantas medicinalmente úteis (...) A utilidade prática do mundo das plantas forneceu por muito tempo aos botânicos o seu princípio organizador mais importante.” (THOMAS, 2010: 73).

${ }^{16}$ Sobre a importância do açúcar para os holandeses e seu peso na tomada de decisão de atacar o Brasil, Marcos Guimarães Sanches aponta que há pensamentos divergentes na historiografia: Para Kossman, o comércio do açúcar era secundário e a WIC havia sido criada com o maior intuito de hostilizar a Espanha. José Gonsalves de Mello defende o oposto, que a economia holandesa era baseada no comércio e que o refino do açúcar, nos Países Baixos, dependia do fornecimento do açúcar brasileiro. A historiografia recente, porém, aponta "que o envolvimento nos negócios do açúcar não é a única causa da ação da Companhia no Brasil, devendo ser levados em conta o quadro internacional, a consolidação das práticas consideradas típicas do mercantilismo e até os primeiros sinais de declínio dos rendimentos do açúcar" (Cf. SANCHES, M. G. "A mais deliciosa, próspera e abundante - A capitania de Pernambuco e o projeto holandês no Brasil” In: TOSTES et ali, 2005, pp. 176-177). 
indígenas faziam da bebida ou da pasta do cacau era como antídoto, função que, como sabemos, muito interessava a Piso. (ALGRANTI, 2009: 409-410)

A maioria das demais plantas descritas são nativas e, muitas delas, pouco conhecidas dos europeus. Geralmente Piso apresenta o nome nativo da planta e, quando há, o nome dado por algum grupo europeu. François Hartog, ao analisar a retórica de alteridade, aponta que citar apenas o nome dado pelo outro, por um lado, demonstra algo importante aos leitores europeus, que é a autoridade do autor perante o assunto, além de fornecer os elementos exóticos tão esperados nesse tipo de retórica, mas, por outro lado, "a ausência de tradução vem a ser verdadeiramente o indício de uma ausência na tabela de equivalências.” (HARTOG, 1999: 258)

E a busca por equivalentes tem sempre como referencial o grupo ao qual pertencem quem conta e a quem algo é contado, nesse caso, o referencial é europeu. Ilustrativo exemplo disso é o seguinte trecho, quando Piso se refere à mandioca:

Até esta época muitas regiões das Índias careceram de trigo; todavia, a benigna mãe Natureza não quis que faltassem aquelas cousas que sustentam a vida dos homens e dos brutos e fazem às vezes de trigo. Pois a raiz cultivada ou tratada, pelos bárbaros chamada Mandihoca, reduzida a farinha e cozida como pão, compete com o melhor pão de flor de farinha. (PISO, 1957 [1658]: 261)

O pão, feito principalmente de trigo, e o vinho ocupam papeis centrais na alimentação ocidental ${ }^{17}$, por isso, não só Piso, mas muitos outros viajantes e cronistas buscaram equivalentes ao pão e ao vinho na América. ${ }^{18}$ Piso comenta ainda sobre o vinho, "ou bebida espirituosa semelhante", feito pelos frutos "Acajü", "Pacóba, Ananás, Mangába, Ianipába, Caraguatá” e ainda feito pela própria raiz de mandioca.

\footnotetext{
${ }^{17}$ Massimo Montanari aponta a importância do pão e do vinho como símbolos da "civilização" para os gregos e romanos, uma vez que demonstra que esta sociedade "não repousa sobre recursos 'naturais', mas que é capaz de fabricar, ela própria, seus recursos". Aponta ainda que que o cristianismo, ao sacralizar o pão e o vinho, assim como o óleo, "reforçará, ainda mais, os valores do modelo alimentar romano" (FLANDRIN; MONTANARI, 1998: 111-118).

${ }^{18}$ Ao que pudemos constatar, também o padre jesuíta Fernão Cardim (Tratados da terra e gente do Brasil, 1583-1601) descreve a mandioca como o principal mantimento do Brasil, que faz o lugar de pão, e Gabriel Soares de Sousa (Tratado descritivo do Brasil, 1587) compara a mandioca com o trigo. O trecho citado de Piso se assemelha à forma com que o jesuíta José de Acosta descreve o pão e o vinho das Índias em seu História Natural e Moral das Índias (1590). Piso cita ainda que Nicolas Monardes "atesta (...) que esta raiz, ali [na América Espanhola] chamada Yuca, por outros mexicanos Quauhcamotli, preparada e reduzida a farinha, é denominada Cassavi." (PISO, 1957 [1658]: 262)
} 
Comparando sua descrição da mandioca com as descrições feitas por Fernão Cardim e Gabriel Soares de Sousa, chama-nos a atenção que, nestas, parece estar mais presente a tentativa de fazer com que seu grupo, a quem eles contam o Novo Mundo, consiga encontrar equivalências, a partir das analogias e comparações entre os dois mundos. Embora esses elementos estejam presentes também na retórica de alteridade construída por Piso, seu interesse parece ser, muito mais, o de fazer ver através da descrição. Elementos da retórica da alteridade, como comparações, muitas vezes são substituídos por uma minuciosa descrição de cores e formas, ou são misturados a elas, como na seguinte passagem (para citar apenas uma), sobre a goiaba:

Dá uma flor composta de cinco folhas e muitos estames como crista de pavão; a esta segue-se o fruto, do tamanho e da forma de uma maçã da nossa terra, não muito diferente, a não ser que é oblongo e de casca mais rugosa; a polpa é de cor sanguínea pálida, cheia de caroços, comestíveis como as nêsperas. (PISO, 1957 [1658]: 337-338)

Além disso, Daniela Calainho aponta que Guilherme Piso, sendo médico e podendo, portanto, testar e comprovar "o efeito terapêutico de várias plantas utilizadas pelos indígenas", foi "além da mera descrição do que via" e realizou o "primeiro relato a dar conta efetivamente da história natural do Brasil, alicerçado nas indicações fundamentais dos índios e de sua medicina." (CALAINHO, 2009: 259). Não queremos, com isso, isentar de alteridade as descrições e o conhecimento produzidos por Piso, a partir do referencial europeu. ${ }^{19}$ Porém nosso intuito é destacar a relação entre alteridade e a necessidade de adaptação à realidade do Novo Mundo, lembrando que, no caso de Piso, essa adaptação deveria corresponder ainda a interesses estratégicos e científicos previamente determinados, quando de seu envio ao nordeste da América portuguesa.

As observações de Guilherme Piso sobre as plantas, os animais, os habitantes e as doenças do Novo Mundo desvelam a complexidade da construção do conhecimento médico e dietético no contexto do século XVII. A própria seleção de Piso para participar da comitiva de Nassau e as tarefas recebidas por ele são indicativas da

\footnotetext{
${ }^{19}$ Para citar um exemplo, Piso assim descreve a pintura com jenipapo feita pelos indígenas: “(...) e com ele pintam o corpo, de jeito que de longe simulam uma veste negra, de aspecto medonho, para que, indo à guerra, pareçam espantosos aos inimigos. Nenhum outro uso tem este suco, excogitado somente para artimanhas" (PISO, 1957 [1658]: 313 grifos nossos). Ao que parece, a repulsa de Piso por esse ato o impediu de conhecer os outros usos do caldo de jenipapo, como seu uso repelente - uso, que, aliás, seria interessante aos europeus, que faziam muitas reclamações sobre os insetos.
} 
condição multifacetada do médico: por um lado, deveria exercer seu ofício, cuidando primeiramente do Príncipe, mas também dos soldados; por outro lado, estava imbuído de observar a natureza local e o que ela poderia fornecer para o exercício de sua profissão, além de buscar aprender as artes de cura dos nativos.

É interessante notar que as diversas facetas dependiam umas das outras e mobilizavam, em Piso, tanto seu conhecimento clássico adquirido nas universidades da Europa, quanto sua capacidade de aprendizado e de construção de um novo saber. Este, por sua vez, deveria articular o conhecimento teórico clássico que Piso já possuía com a observação, experimentação e inquirição das novidades e com os ensinamentos dos povos indígenas, tensionados pela relação de alteridade posta entre europeu e ameríndio. Todo esse processo desnudou as controvérsias e mudanças de paradigma pelas quais passava o conhecimento médico no Velho Mundo, mas também se mostrou condição salutar para a própria sobrevivência no Novo Mundo.

\section{Fonte}

PISO, Guilherme. (1957 [1658]). História Natural e Médica da Índia Ocidental: em cinco livros. Trad. por Mario Lobo Leal. Rio de Janeiro, RJ: Instituto Nacional do Livro.

\section{Referências Bibliográficas}

ALFONSO-GOLDFARB, Ana Maria. (1994) O que é história da Ciência. Coleção Primeiros Passos. São Paulo: Editoria Brasiliense.

ALGRANTI, Leila Mezan; MEGIANI, Ana Paula Torres (orgs.) (2009) O império por escrito. São Paulo: Alameda.

BOXER, Charles. (1961) Os holandeses no Brasil - 1624-1654. São Paulo: Companhia Editorial Nacional.

CALAINHO, Daniela Buono. (2009) Cruzando mares: drogas medicinais do Brasil no império português. In: MONTEIRO, R.B. e VAINFAS, R. Império de várias faces: relações de poder no mundo ibérico da Época Moderna. São Paulo: Alameda, pp. 255-271.

CARNEIRO, Henrique. (2011) O saber fitoterápico indígena e os naturalistas europeus. Fronteiras (Dourados), Mato Grosso do Sul, v. 13, n. 23, pp. 13-32, jan-jun.

DEBUS, Allen G. (1996) El hombre y la naturaleza en el renacimiento. México, D.F. : Breviários Fondo de Cultura Econômica. 
FLANDRIN, Jean-Louis; MONTANARI, Massimo. História da Alimentação. 2. ed. São Paulo: Estação Liberdade, 1998.

GARIN, Eugenio (org.) (1991) O homem renascentista. Lisboa: Editorial Presença.

GESTEIRA, H.M. (2004) A cura do corpo e a conversão da alma: conhecimento da natureza e conquista da América, séculos XVI e XVII. Topoi (Rio de Janeiro), Rio de Janeiro, v. 5, n.8, jan-jun 2004, pp. 71-95.

. (2006) A História Natural do Colonialismo Holandês. Insight Inteligência (Rio de Janeiro), Rio de Janeiro, v. Ano IX, nº 33, pp. 105-117.

(2004) O Recife Holandês: história natural e colonização neerlandesa (16241654). Revista da Sociedade Brasileira de História da Ciência, Rio de Janeiro, v.2, n.1, pp. 6-21.

. (2001) Teatro das coisas naturais: conhecimento e dominação neerlandesa no Brasil. Tese (Doutorado em História Social) - Universidade Federal Fluminense, Rio de Janeiro: Niterói.

HARTOG, François. (1999) O espelho de Heródoto: ensaio sobre a representação do outro. Belo Horizonte: Ed. UFMG.

HERKENHOFF, Paulo (org.) (1999) O Brasil e os holandeses: 1630 - 1654. Rio de Janeiro: GMT Editores/Sextante Artes.

HOLANDA, Sérgio Buarque de. (1994) Caminhos e fronteiras. São Paulo: Companhia das Letras.

22 KUHN, Thomas. (2009 [1962]) A estrutura das revoluções cientificas. São Paulo, SP: Perspectiva.

LAURIOX, Bruno. (1998) Cozinhas medievais (séculos XIV e XV). In: FLANDRIN, Jean-Louis; MONTANARI, Massimo. História da Alimentação. 2. ed. São Paulo: Estação Liberdade, pp. 447-477

LEMPS, Alain Hurtz de. (1998) As bebidas coloniais e a rápida expansão do açúcar. In: FLANDRIN, Jean-Louis; MONTANARI, Massimo. História da Alimentação. 2. ed. São Paulo: Estação Liberdade, pp. 611-666.

LOPEZ, Adriana. (2002) Guerra, açúcar e religião no Brasil dos holandeses. São Paulo: Editora Senac São Paulo.

MAZZINI, Innocenzo. (1998) A alimentação e a medicina no mundo antigo. In: FLANDRIN, Jean-Louis; MONTANARI, Massimo. História da Alimentação. 2. ed. São Paulo: Estação Liberdade, pp. 254-277.

MELLO, Evaldo Cabral de. (org.) (2010) O Brasil Holandês (1630 - 1654). São Paulo: Penguin Classics.

RIBEIRO, Márcia Moisés. (1997) A ciência dos trópicos - a arte médica no Brasil do século XVIII. São Paulo: Editora Hucitec.

SHAPIN, Steven. (2000) La Revolución científica: una interpretación alternativa. Barcelona: Ediciones Paidós Ibérica.

THOMAS, Keith. (2010) O homem e o mundo natural: mudança de atitudes em relação às plantas e aos animais (1500 - 1800). São Paulo: Companhia das Letras. 
TOSTES, V.L.B; BENCHETRIT, S.F.; MAGALHÃES, A.M. (orgs.) (2005) A presença holandesa no Brasil: memória e imaginário. (2004) Rio de Janeiro: Museu Histórico Nacional.

Artigo recebido em 5 de fevereiro de 2016.

Aprovado em 03 de maio de 2016.

DOI: 10.12957/intellectus.2016.22265 